\title{
ZOONOTIC ONCHOCERCIASIS IN HIROSHIMA, JAPAN, AND MOLECULAR ANALYSIS OF A PARAFFIN SECTION OF THE AGENT FOR A RELIABLE IDENTIFICATION
}

\author{
FUKUDA M.***, OTSUKA Y.**, UNI S.***, BODA T.****, DAISAKU H.****, \\ HASEGAWA H.******, TAKAOKA H.**,******** \& BAIN O.*********
}

\section{Summary:}

Japan is a country of high specific diversity of Onchocerca with eight species, the adults of two not yet known. Onchocerca dewittei japonica, a common filarial parasite of wild boar, had been proved to be the agent of five zoonotic onchocerciasis in Kyushu island with morphological and molecular studies. The sixth case, at Hiroshima in the main island, was identified to the same Onchocerca species, based on adult characters observed on histological sections. To consolidate the identification, mitochondrial cytochrome c oxidase subunit 1 (CO1) gene analysis was attempted with the formalin-fixed, paraffin-embedded parasite specimen. The sequence (196 bp) of a CO1 gene fragment of the parasite successfully PCR-amplified agreed well with those of $O$. dewittei japonica registered in GenBank, confirming the morphological identification. Moreover a comparison with the $\mathrm{CO} 1$ gene sequences of six other Onchocerca species in GenBank excluded the possibility that Onchocerca sp. from wild boar and Onchocerca sp. type A from cattle in Japan, were the causative agents in this case. Mitochondrial DNA analysis proved to be a valuable tool to support the morphological method for the discrimination of zoonotic Onchocerca species in a histological specimen.

KEY WORDS: zoonotic onchocerciasis, Onchocerca dewittei japonica, mitochondrial DNA analysis, Japan.

$\mathrm{H}$ uman zoonotic onchocerciasis is rare. Only 16 cases have so far been reported in the world, including six cases in Japan, five from Oita, Kyushu, and the most recent from Hiroshima (Uni et al., 2010). The causative agents of all the Japanese cases were identified as Onchocerca dewittei

\footnotetext{
* Research Promotion Project, Oita University, Hasama, Yufu, Oita 879-5593, Japan.

** Department of Infectious Disease Control, Faculty of Medicine, Oita University, Hasama, Yufu, Oita 879-5593, Japan.

*:* Department of Medical Zoology, Osaka City University Medical School, Abeno-ku, Osaka 545-8585, Japan.

****: Shobara Red Cross Hospital, Shobara, Hiroshima 727-0013, Japan.

****:* Department of Biology, Faculty of Medicine, Oita University, Hasama, Yufu, Oita 879-5593, Japan.

******** Institute of Biological Sciences, Faculty of Science, University of Malaya, Kuala Lumpur, 50603, Malaysia.

**:**:***: Parasitologie comparée et Modèles expérimentaux, USM307, Muséum National d'Histoire Naturelle, 75231 Paris, France.

Correspondence: Masako Fukuda.

Tel.: 81975865702 - Fax: 81975865702 .

E-mail: mfukuda@oita-u.ac.jp
}

Résumé : ONCHOCERCOSE ZOONOTIQUE À HIROSHIMA, JAPON, ET ANALYSE MOLÉCULAIRE D'UNE COUPE HISTOLOGIQUE DE L'AGENT POUR CONFORTER L'IDENTIFICATION

Le Japon est une région de grande diversité du genre Onchocerca avec huit espèces, dont deux identifiées par les microfilaires, les adultes étant encore inconnus. Il a été démontré par les analyses morphologiques et moléculaires qu'Onchocerca dewittei japonica, filaire fréquente du cochon sauvage, est l'agent des cinq cas d'onchocercose zoonotique dans l'île de Kyushu. Le sixième cas, à Hiroshima, île principale, a été identifié à la même espèce d'onchocerque d'après les caractères de l'adulte observés sur coupes histologiques. Afin de vérifier cette identification, I'analyse du gène mitochondrial de la sous-unité 1 de la cytochrome c oxydase (CO1) a été effectuée avec une coupe du specimen fixé au formol et inclus en paraffine. La séquence (196 bp) d'un fragment du gène CO1 du parasite, amplifié par PCR, est semblable à celles $d^{\prime} O$. dewittei japonica enregistrées dans GenBank, confirmant l'identification morphologique. En outre, la comparaison avec les séquences du gène CO1 de six autres espèces d'Onchocerca déposées dans cette base de données exclut comme agents possibles Onchocerca sp. du sanglier et Onchocerca sp. type $A d u$ bétail au Japon. L'analyse de l'ADN mitochondrial est donc un outil valable qui complète la méthode morphologique de discrimination des espèces zoonotiques d'onchocerques sur coupes histologiques.

MOTS-CLÉS : onchocercose zoonotique, Onchocerca dewittei japonica, analyse de l'ADN mitochondrial, Japon.

japonica Uni, Bain \& Takaoka, 2001, a common filarial parasite of wild boar (Sus scrofa Linnaeus) in Japan (Uni et al., 2001), based on the morphological characteristics of the adult worms (Beaver et al., 1989; Hashimoto et al., 1990; Takaoka et al., 1996, 2001, 2004, 2005; Uni et al., 2010). As for the first two cases, the species was confirmed retrospectively because at that time $O$. dewittei japonica had not yet been discovered (Takaoka et al., 2001; Uni et al., 2010).

In Japan, six other Onchocerca species are known (Takaoka et al., 2005; Uni et al., 2007): three cosmopolitan parasites of domestic animals, O. cervicalis Railliet and Henry, 1910 from horses, O. gutturosa Neumann, 1910, and O. lienalis (Stiles, 1982) from cattle; three of wild animals, O. eberhardi Uni \& Bain, 2007 from sika deer (Cervus nippon Temminck), O. skrjabini Rukhlyadev, 1964 from sika deer and serows (Capricornis crispus Temminck), and $O$. suzukii Yagi, Bain \& Shoho, 1994 from serows. 
Recently another Onchocerca species was found from wild boars in Japan (Fukuda et al., 2008, 2010a). This unnamed species, the adult of which is unknown, is distinguishable from $O$. dewittei japonica by the body size of the microfilaria (Fukuda et al., 2008). In addition, there is another unnamed Onchocerca species (its adults unknown) found from cattle in Japan (Takaoka \& Bain, 1990). This, designated as type A, is also distinguished from other Onchocerca species by the morphology of the microfilaria and the infective larva (Takaoka \& Bain, 1990; Fukuda et al., 2010b). Thus, there remains the possibility that either of these two unnamed species was involved as the causative agent of all or some of six Japanese cases so far reported. On the other hand, we have already shown that both of these two unnamed species are distinguishable from $O$. dewittei japonica by the mitochondrial cytochrome $c$ oxidase subunit 1 (CO1) gene analysis (Fukuda et al., 2010a, 2010b).

In order to investigate the possibility of one of the two unnamed Onchocerca species being the causative agent of the sixth case of zoonotic onchocerciasis in Japan (Uni et al., 2010), we performed the mitochondrial DNA analysis for a formalin-fixed, paraffinembedded parasite specimen.

\section{MATERIALS AND METHODS}

\section{SPECIMEN EXAMINED}

A tissue sample stored as a paraffin block of the sixth case of zoonotic onchocerciasis in Japan was examined, where the worm found in the histological sections had been already identified as female O. dewittei japonica based on its morphology (Fig. 1) (Uni et al., 2010). In short, in July 2009, a subcutaneous nodule $(2 \mathrm{~cm}$ in diameter) was surgically removed from the left knee of the patient, a 70-year-old man living in Hiroshima Prefecture, Japan. The tissue excised $(1 \times 2 \mathrm{~cm})$ was fixed in $4 \%$ paraformaldehyde for $24 \mathrm{hr}$ and embedded in paraffin by a routine procedure (Uni et al., 2010). For molecular analysis the section was cut at thickness of $20 \mu \mathrm{m}$.

\section{DNA EXTRACTION}

The tissue of the worm (ca. $2.8 \mathrm{~mm}^{2}$ ) was scraped from the section on a glass slide with a disposable sterilized scalpel blade and transferred into a $1.5 \mathrm{ml}$ microcentrifuge tube. The tissue was incubated with $0.5 \mathrm{ml}$ of DEXPAT (Takara Bio Inc., Otsu, Japan) for $10 \mathrm{~min}$ at $100{ }^{\circ} \mathrm{C}$ and then centrifuged for $10 \mathrm{~min}$ at $12,000 \mathrm{rpm}$ at $4{ }^{\circ} \mathrm{C}$. Ten microliters of the supernatant was used as template DNA for PCR.

\section{PCR AND SEQUENCING OF THE PARTIAL MITOCHONDRIAL CO1 GENE REGION}

Two primer sets, general filarial primers CO1intFCO1intR (Casiraghi et al., 2001) and newly designed CO1fF (5'-TTGTCTGTTCCTGTTTTGG-3')-CO1fR (5'GCAAAAGTTATTCTAGTTTGACCA-3') respectively, were used to amplify a fragment of the mitochondrial CO1 gene (coding sequence). CO1fF-CO1fR was constructed inside COlintF-CO1intR on the basis of the known sequences of Onchocerca species in Japan. The positions of the primers on the complete mitochondrial genome of O. volvulus (GenBank accession

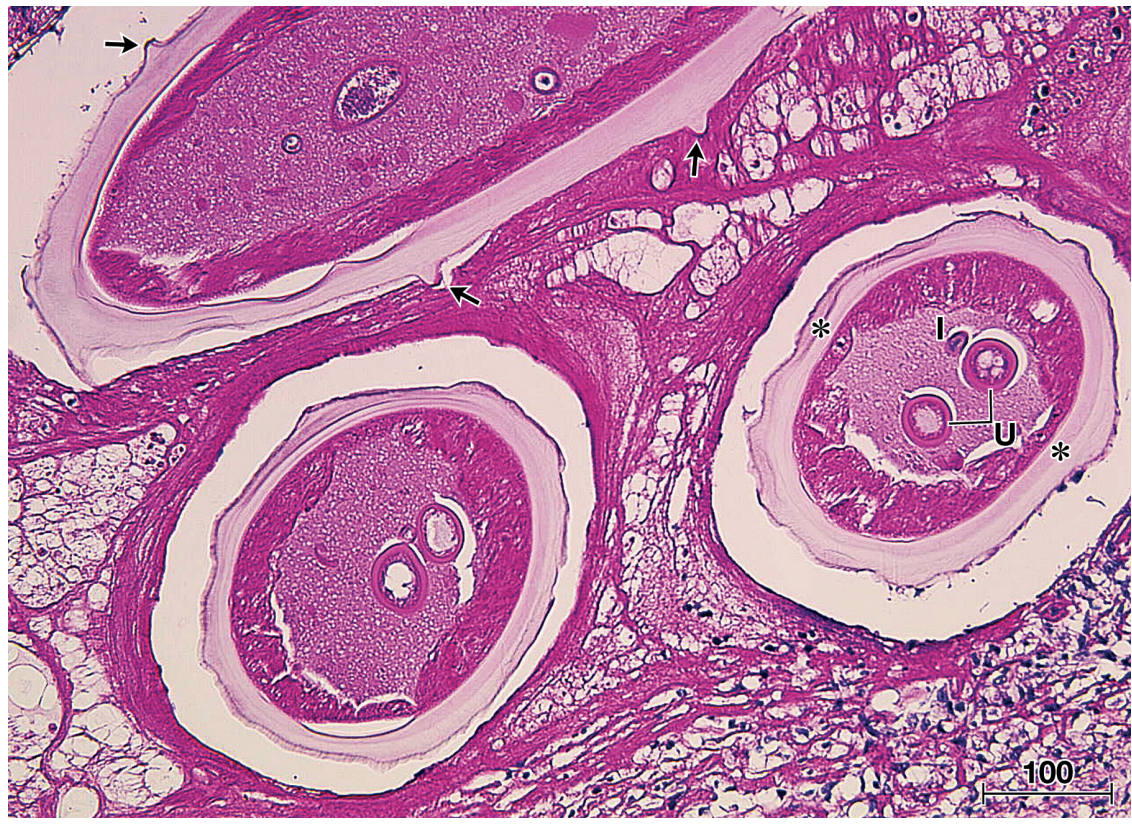

Fig. 1. - Histological section of a nodule showing the worm and surrounding tissue excised from the patient.

Morphological characteristics of the female worm identified as Onchocerca dewittei japonica showing the salient transverse ridges (arrows), lateral chords $\left(^{*}\right)$, uteri (U), and intestine (I).

The section is stained with hematoxylin and eosin. Bar, micrometers. 
number: AF015193) are: CO1intF, 2519-2538; CO1intR, 3207-3186; CO1fF, 2884-2902; CO1fR, 3099-3122. Amplifications were performed in $50 \mu \mathrm{l}$ containing $1 \times$ buffer for KOD -Plus- Ver.2 (Toyobo, Osaka, Japan), $1.5 \mathrm{mM} \mathrm{MgSO}_{4}, 200 \mu \mathrm{M}$ each of dNTPs, $0.1 \mu \mathrm{M}$ each of primers, 0.5 units of KOD -Plus- (Toyobo), and $10 \mu \mathrm{l}$ of template DNA. The thermal conditions were as follows: larger fragments (689 bp), an initial denaturation at $94^{\circ} \mathrm{C}$ for $2 \mathrm{~min}$, followed by five cycles of $98^{\circ} \mathrm{C}$ for $10 \mathrm{~s}, 55^{\circ} \mathrm{C}$ for $30 \mathrm{~s}$, and $68^{\circ} \mathrm{C}$ for $45 \mathrm{~s}$ and 37 cycles of $98{ }^{\circ} \mathrm{C}$ for $10 \mathrm{~s}, 48^{\circ} \mathrm{C}$ for $30 \mathrm{~s}$, and $68{ }^{\circ} \mathrm{C}$ for $45 \mathrm{~s}$; smaller fragments $(239 \mathrm{bp})$, an initial denaturation at $94{ }^{\circ} \mathrm{C}$ for $2 \mathrm{~min}$, followed by five cycles of $98{ }^{\circ} \mathrm{C}$ for $10 \mathrm{~s}, 60{ }^{\circ} \mathrm{C}$ for $30 \mathrm{~s}$, and $68{ }^{\circ} \mathrm{C}$ for $30 \mathrm{~s}$ and 37 cycles of $98{ }^{\circ} \mathrm{C}$ for $10 \mathrm{~s}, 55^{\circ} \mathrm{C}$ for $30 \mathrm{~s}$, and $68^{\circ} \mathrm{C}$ for $30 \mathrm{~s}$.

PCR products were purified with a QIAquick PCR Purification Kit (QIAGEN, Hilden, Germany) and directly sequenced using the primers for PCR, a BigDye Terminator v3.1 Cycle Sequencing Kit (Applied Biosystems, Foster City, CA, USA), and an Applied Biosystems 3130 Genetic Analyzer (Applied Biosystems). PCRs were conducted twice and each of the amplification products were sequenced. The sequence determined was deposited in DDBJ/EMBL/GenBank databases under the accession number AB604943 (Table I).

\section{DATA ANALYSIS}

The sequence obtained was aligned with published sequences of seven Onchocerca species in Japan. Using this alignment, sequences were compared by MEGA 4.0.2 based on 196 bp available for comparison (Tamura et al., 2007). Used GenBank database accession numbers were as follows: O. dewittei japonica (AM749266, AB518874, AB518875), O. eberhardi (AM749268), O. gutturosa (AJ271617), O. skrjabini (AM749269), O. sp. type A sensu Fukuda et al., 2010 (AB518876), O. sp. wild boar sensu Fukuda et al., 2010 (AB518693), and O. suzukii (AM749275).

\section{RESULTS AND DISCUSSION}

T The mitochondrial CO1 gene was not amplified with the CO1intF-CO1intR primers (expected size: $689 \mathrm{bp}$ ), which are proved to generate products from various filarial species (Casiraghi et al., 2001; Fukuda et al., 2010a, 2010b). This was probably due to the degradation of DNA because the specimen (Fig. 1) was fixed in paraformaldehyde and embedded in paraffin (Bianchi et al., 1991). Thus the new primers, CO1fF-CO1fR, were designed inside the CO1intF-CO1intR and a 239 bp-gene fragment was successfully amplified. The sequence (excluding primers) determined was $196 \mathrm{bp}$ long and was compared with those of all seven Onchocerca species of Japan available in GenBank. Table I shows the nucleotide differences among Onchocerca species in Japan. The numbers of nucleotide differences between the present specimen and $O$. dewittei japonica ranged from 0 to 2, small enough to assure the conspecific status, while those between the present specimen and other Onchocerca species ranged from 15 to 21 . The differences between the present specimen and the two undescribed species, $O$. sp. from wild boar and $O$. sp. type A from cattle, were 19 and 21, respectively, suggesting that neither of them was the causative species.

The causative agents of zoonotic onchocerciasis are relatively difficult to identify morphologically, particularly if the available specimens are restricted to histological sections, or the fauna of Onchocerca species and their definitive natural hosts in the areas where zoonotic onchocerciases occurred are unknown, as shown in most of the previous cases of zoonotic onchocerciasis. On the other hand, molecular analysis can directly identify the causative species as shown by Koehsler et al. (2007) who identified O. jakutensis (Gubanov, 1964), a parasite of red deer (Cervus ela-

\begin{tabular}{|c|c|c|c|c|c|c|c|c|c|c|c|}
\hline & & 1 & 2 & 3 & 4 & 5 & 6 & 7 & 8 & 9 & 10 \\
\hline $\mathbf{1}$ & This study (O. dewittei japonica Hiroshima*, AB604943) & & 0 & 1 & 2 & 19 & 21 & 15 & 18 & 20 & 20 \\
\hline 2 & O. dewittei japonica (AB518874) & 0 & & 1 & 2 & 19 & 21 & 15 & 18 & 20 & 20 \\
\hline 3 & O. dewittei japonica (AM749266) & 0.5 & 0.5 & & 1 & 18 & 20 & 14 & 17 & 19 & 19 \\
\hline 4 & O. dewittei japonica (AB518875) & 1.0 & 1.0 & 0.5 & & 17 & 21 & 13 & 18 & 18 & 18 \\
\hline 5 & O. sp. wild boar & 9.7 & 9.7 & 9.2 & 8.7 & & 20 & 13 & 18 & 13 & 18 \\
\hline 6 & O. sp. type A & 10.7 & 10.7 & 10.2 & 10.7 & 10.2 & & 20 & 15 & 15 & 14 \\
\hline 7 & O. eberhardi & 7.7 & 7.7 & 7.1 & 6.6 & 6.6 & 10.2 & & 17 & 12 & 13 \\
\hline 8 & O. suzukii & 9.2 & 9.2 & 8.7 & 9.2 & 9.2 & 7.7 & 8.7 & & 15 & 11 \\
\hline 9 & O. skrjabini & 10.2 & 10.2 & 9.7 & 9.2 & 6.6 & 7.7 & 6.1 & 7.7 & & 8 \\
\hline 10 & O. gutturosa & 10.2 & 10.2 & 9.7 & 9.2 & 9.2 & 7.1 & 6.6 & 5.6 & 4.1 & \\
\hline
\end{tabular}

Values above the diagonal are the numbers of nucleotide differences, and those below the diagonal are the percentages of nucleotide differences. * Diagnosis by morphological observation.

Table I. - Nucleotide differences over 196 sites of the CO1 gene sequences among Onchocerca species in Japan. 
phus Linnaeus), as the causative species from a histological section of a patient in Austria.

In the present study, we could also prove that DNA analysis of mitochondrial $\mathrm{CO} 1$ gene region was a very effective method for the accurate identification of the causative species of zoonotic onchocerciasis in an area where the relevant molecular data are comparatively well documented on Onchocerca species including ones of which adults remain unknown. Although we used a $20 \mu$ m-thick section of paraffin-embedded tissue for molecular analysis to investigate the possibility of the two undescribed species as a causative agent, species identification from a section with a usual thickness of $4 \mu \mathrm{m}$ may be possible, but is yet to be confirmed. This type of molecular analysis will be a useful tool for the definitive diagnosis in similar cases of zoonotic onchocerciasis in future.

In conclusion, our study suggests that mitochondrial DNA analysis is a useful tool to support the traditional morphological method for species identification of the causative agent of zoonotic onchocerciasis in view of the fact that few specimens, especially histological sections, are available and the life cycle of the causative species is uninvestigated.

\section{ACKNOWLEDGEMENTS}

TVTe thank Dr. Yoshihiro Ikura, Department of Wathology, Osaka City University Medical School, for his helpful suggestions. We are grateful to Dr. Deirdre McIntosh for English proofreading. This study was supported in part by the MNHN grant ATM "Taxonomie moléculaire : DNA barcode et gestion des collections".

\section{REFERENCES}

Beaver P.C., Yoshimura H., Takayasu S., Hashimoto H. \& LiTTLE M.D. Zoonotic Onchocerca in a Japanese child. The American Journal of Tropical Medicine and Hygiene, 1989, 40, 298-300.

Bianchi A.B., Navonne N.M. \& Conti J.C. Detection of loss of heterozygosity in formalin-fixed paraffin-embedded tumor specimens by the polymerase chain reaction. The American Journal of Pathology, 1991, 138, 279-284.

Casiraghi M., Anderson T.J.C., Bandi C., Bazzocchi C. \& GENCHI C. A phylogenetic analysis of filarial nematodes: comparison with the phylogeny of Wolbachia endosymbionts. Parasitology, 2001, 122, 93-103.

Fukuda M., Otsuka Y., Uni S., Bain O. \& Takaoka H. Genetic evidence for the presence of two species of Onchocerca from the wild boar in Japan. Parasite, 2010a, 17, 33-37.

Fukuda M., Otsuka Y., Uni S., Bain O. \& Takaoka H. Molecular identification of infective larvae of three species of
Onchocerca found in wild-caught females of Simulium bidentatum in Japan. Parasite, 2010b, 17, 39-45.

FuKuda M., TAKaOKa H., Uni S. \& Bain O. Infective larvae of five Onchocerca species from experimentally infected Simulium species in an area of zoonotic onchocerciasis in Japan. Parasite, 2008, 15, 111-119.

Hashimoto H., Murakami I., Fujiwara S., Takayasu S., Takaoka H., Uga S., AkaO N., Kondo K. \& Yoshimura H. A human case of zoonotic onchocerciasis in Japan. The Journal of Dermatology, 1990, 17, 52-55.

Koehsler M., Soleiman A., Aspöck H., Auer H. \& Walochnik J. Onchocerca jakutensis filariasis in humans. Emerging Infectious Diseases, 2007, 13, 1749-1752.

TAKAOKA H. \& BaIN O. Infections of blackflies (Diptera: Simuliidae) with three types of zoonotic Onchocerca larvae in Oita, Japan. Japanese Journal of Tropical Medicine and Hygiene, 1990, 18, 1-10.

Takaoka H., Bain O., Tajimi S., Kashima K., Nakayama I., Korenaga M., Aoki C. \& Otsuka Y. Second case of zoonotic Onchocerca infection in a resident of Oita in Japan. Parasite, 1996, 3, 179-182.

Takaoka H., Bain O., Uni S., Korenaga M., Kozek W.J., ShIrasaka C., Aoki C., Otsuka Y., Fukuda M., Eshita Y. \& DaA T. Zoonotic onchocerciasis caused by a parasite from wild boar in Oita, Japan. A comprehensive analysis of morphological characteristics of the worms for its diagnosis. Parasite, 2004, 11, 285-292.

Takaoka H., Bain O., Uni S., Korenaga M., Tada K., IchiKawa H., OTSUKA Y. \& EshitA Y. Human infection with Onchocerca dewittei japonica, a parasite from wild boar in Oita, Japan. Parasite, 2001, 8, 261-263.

Takaoka H., Yanagi T., DaA T., Anzai S., Aoki C., Fukuda M., Uni S. \& Bain O. An Onchocerca species of wild boar found in the subcutaneous nodule of a resident of Oita, Japan. Parasitology International, 2005, 54, 91-93.

Tamura K., Dudley J., Nei M. \& Kumar S. MEGA4: Molecular evolutionary genetics analysis (MEGA) software version 4.0. Molecular Biology and Evolution, 2007, 24, 15961599.

Uni S., Bain O., Agatsuma T., Harada M., Toril H., Fukuda M. \& TАКАОКА H. Onchocerca eberhardi n. sp. (Nematoda: Filarioidea) from sika deer in Japan; relationships between species parasitic in cervids and bovids in the Holarctic region. Parasite, 2007, 14, 199-211.

Uni S., Bain O., TAKaOKa H., Miyashita M. \& SuZuki Y. Onchocerca dewittei japonica n. subsp., a common parasite from wild boar in Kyushu Island, Japan. Parasite, 2001, 8, 215-222.

Uni S., Boda T., Daisaku K., Ikura Y., Maruyama H., Hasegawa H., FuKuda M., TAKaOKa H. \& Bain O. Zoonotic filariasis caused by Onchocerca dewittei japonica in a resident of Hiroshima Prefecture, Honshu, Japan. Parasitology International, 2010, 59, 477-480.

Received on October $6^{\text {th }}, 2010$ Accepted on December 29 $9^{\text {th }}, 2010$ 